\title{
Potentiation of Human Immunoglobulin E Synthesis by Plasma Immunoglobulin E Binding Factors from Patients with the Hyperimmunoglobulin E Syndrome
}

\author{
Donald Y. M. Leung, Rene Frankel, Nancy Wood, and Raif S. Geha \\ Division of Allergy, The Children's Hospital, Boston, Massachusetts 02115; Department of Pediatrics, \\ Harvard Medical School, Boston, Massachusetts 02115
}

\begin{abstract}
Affinity-purified IgE-binding factors from the plasma of patients with the hyper IgE syndrome (HIE) were assessed for their capacity to enhance IgE synthesis by $B$ cells derived from patients with allergic rhinitis or normal nonatopic donors. IgE-binding factors from three of four HIE patients enhanced IgE synthesis by $B$ cells from patients with perennial allergic rhinitis, or with seasonal allergic rhinitis (SAR) and recent pollen exposure, but did not enhance IgE synthesis by B cells from nonatopic donors or from SAR patients with no recent pollen exposure. IgG synthesis was not affected by HIE IgE binding factors. In contrast, IgE binding factors from three of three nonatopic donors failed to enhance IgE or IgG synthesis. Plasma IgE-binding factors from the fourth patient with HIE contained a mixture of IgEpotentiating activity and IgE-suppressive activity. These two activities could be separated on concanavalin A Sepharose or peanut agglutinin agarose columns. Human IgE potentiating factor, but not IgE suppressive factor, had affinity for concanavalin $A$ but not peanut agglutinin and fractionated into two peaks on gel filtration over Sephadex G-75: one peak with a molecular size of $\sim 15,000 \mathrm{D}$ and the other with a molecular size of $\sim 60,000$ D. The isolation of functional IgE binding factors which potentiate IgE synthesis from the plasma of patients with HIE suggests that IgE-binding factors play an important role in the in vivo regulation of IgE synthesis in man.
\end{abstract}

\section{Introduction}

Extensive studies by Ishizaka (1) have demonstrated the existence of rat $\mathrm{T}$ cell factors which have affinity for homologous IgE and which selectively regulate the IgE response. Rat IgE binding factors consist of two activities: IgE-potentiating factors (2) and IgE-suppressive factors (3). IgE potentiating factors are secreted by $T$ cells from rats subjected to immunization regimens which are favorable for the formation of IgE antibodies whereas IgEsuppressive factors are secreted by $\mathrm{T}$ cells from rats immunized under conditions which favor IgG but not IgE responses. Both factors had a molecular weight of $\sim 15,000$ but differed in their carbohydrate content. The IgE-potentiating factor(s) had affinity for lentil lectin and concanavalin A (Con A). The IgE-suppressive factor failed to bind to the lectins but had affinity for peanut

Address reprint requests to Dr. Leung, Division of Allergy, The Children's Hospital, 300 Longwood Ave., Boston, MA 02115.

Received for publication 22 March 1985 and in revised form 7 November 1985

J. Clin. Invest.

(C) The American Society for Clinical Investigation, Inc.

0021-9738/86/03/0952/06 \$1.00

Volume 77, March 1986, 952-957 agglutinin (PNA) ${ }^{1}$ (4). Subsequent experiments by the same group of investigators revealed that human $T$ lymphocytes activated during the course of a mixed lymphocyte reaction, as well as normal human $\mathrm{T}$ cells that proliferated in the presence of interleukin 2 formed IgE-binding factors upon incubation with IgE (5). IgE-binding factors were also detected in the serum of patients with atopic dermatitis (1). The functional activity of these human IgE-binding factors have not, to date, been reported.

Our laboratory has used the hyper IgE syndrome (HIE) as a disease model for the study of human IgE synthesis. These patients have extremely high IgE levels $(6,7)$ and their circulating $T$ cells spontaneously secrete soluble factors which potentiate IgE synthesis $(8,9)$. Furthermore, long-term $T$ cell lines bearing Fc receptors for IgE from patients with HIE enhance IgE synthesis via the production of IgE-binding factors (10). The potential in vivo significance of human IgE-binding factors is suggested by our recent observation that sera from nonatopic individuals contain low molecular weight IgE-binding factors which suppress IgE but not IgG synthesis in vitro (11). Human IgE suppressor factor had minimal affinity for lentil lectin but bound to PNA. Kishimoto and co-workers (12) have also reported the secretion of human IgE-binding factors that selectively suppress human IgE synthesis by lymphocytes from individuals infected with the tubercle bacillus.

The aim of the present investigation was to determine whether circulating IgE-binding factors from patients with HIE potentiate IgE synthesis. The results obtained demonstrate that IgE-binding factors in hyper IgE plasma contain IgE-specific potentiating factors that act on B cells from patients with allergic rhinitis but not on B cells from normal donors. Human IgEpotentiating factor(s) had affinity for Con A but not PNA, and fractionated into two peaks on gel filtration: one peak with a molecular mass of $\sim 15,000 \mathrm{D}$ and another with a molecular mass of $\sim 60,000 \mathrm{D}$.

\section{Methods}

Plasma samples. Plasma was obtained from four patients with the HIE and three nonatopic controls (serum IgE $<20 \mathrm{IU} / \mathrm{ml}$ ). The diagnosis of HIE was based on a history of recurrent sinopulmonary infections and skin abscesses predominantly with Staphylococcus aureus, chronic eczematoid dermatitis, and marked elevations of serum IgE ranging from 24,000 to $120,000 \mathrm{IU} / \mathrm{ml}$. Plasma was collected in the presence of a 1:20 dilution of a proteolytic enzyme inhibitor cocktail ( $100 \mathrm{mM}$ phenylmethyl sulfonyl fluoride, $100 \mathrm{mM}$ benzamidine, $100 \mathrm{mM}$ NaEDTA, and $0.1 \% \mathrm{Na}$ azide) and centrifuged three times through Diaflo CF50A membranes (Amicon Corp., Lexington, MA) to obtain plasma filtrates free of $\operatorname{IgE}(<150 \mathrm{pg} \mathrm{IgE/ml})$.

1. Abbreviations used in this paper: Con A, concanavalin A; E, sheep erythrocyte; $E^{\prime}-\mathrm{IgE}$, ox erythrocyte coated with human $\mathrm{IgE} ; \mathrm{Fc}_{\ell} \mathrm{R}$, receptor for Fc portion of IgE; HIE, hyper IgE syndrome; HS, horse serum; PNA, peanut agglutinin; SAR, seasonal allergic rhinitis. 
To obtain sufficient IgE-binding factor(s) for Sephadex G-75 gel filtration studies (see below), it was necessary to use plasma obtained during the plasmapheresis of HIE patient no. 2 (Table II). $200 \mathrm{ml}$ from the initial plasmapheresis was used for these studies. This patient was undergoing a course of plasmapheresis for treatment of complications (blindness due to recurrent corneal ulcerations and severe recurrent infections) from her underlying disease since plasma exchange has been found to transiently correct many of the immunologic abnormalities and reverse the tissue inflammation associated with this disease (13). The plasmapheresis was done with full knowledge and approval of the Human Investigations Committee at Children's Hospital, Boston, and with the informed consent of the patient and her parents.

Isolation of IgE-binding factors. The IgE-binding factors in plasma filtrates were isolated by absorption to IgE immobilized to Sepharose, which was prepared by coupling $10 \mathrm{mg}$ of purified human IgE (P.S.) (a kind gift of Dr. K. Ishizaka, Johns Hopkins University, Baltimore, $\mathrm{MD}$ ) to $2 \mathrm{ml}$ of Sepharose 4B CNBr-activated beads (Pharmacia Fine Chemicals, Piscataway, NJ). A 5-ml aliquot of plasma filtrate was continuously cycled through $1 \mathrm{ml}$ of IgE-Sepharose packed in a small column by using a peristaltic pump (LKB, Stockholm, Sweden) which connected the effluent tubing into the head of the column. After $20 \mathrm{~h}$ of continuous cycling at $4^{\circ} \mathrm{C}$, the effluent supernatants were collected; and the beads were then washed with $50 \mathrm{ml}$ of phosphate-buffered saline (PBS) -0.05 $\mathrm{M} \alpha$-lactose to remove nonspecifically absorbed proteins, and then, eluted with $0.1 \mathrm{M}$ glycine-HCL buffer, $\mathrm{pH} 3.0$, at $4^{\circ} \mathrm{C}$. Eluates were collected into tubes that contained an appropriate volume of $0.1 \mathrm{M}$ Tris- $\mathrm{HCl}$

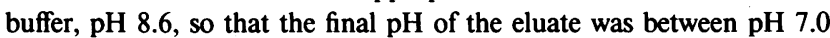
and 8.0. Eluates were dialyzed against RPMI-1640 medium and then concentrated to their original plasma filtrate volume.

Fractionation of IgE-binding factors. IgE-binding factors from HIE plasma filtrates were fractionated by gel filtration through a Sephadex G75 column (Pharmacia; Uppsala, Sweden) $(1.5 \times 95 \mathrm{~cm})$. The column was calibrated with bovine serum albumin $(68,000 \mathrm{D})$, ovalbumin $(48,000$ D), chymotrypsinogen $(25,000 \mathrm{D})$, and ribonuclease A (12,800 D). IgEbinding factor preparations were concentrated 100 -fold by ultrafiltration through a YM2 Amicon membrane (Amicon Corp.), and a 1-ml sample was applied to the Sephadex column in the presence of bovine serum albumin. The column was eluted with PBS and 2-ml fractions were collected.

In some experiments, plasma-derived IgE-binding factors were fractionated on lectin-coupled Sepharose (Pharmacia, Piscataway, NJ), as previously described (11). Con A-Sepharose and agarose coupled with PNA were purchased from Pharmacia Fine Chemicals and Sigma Chemical Co., respectively. IgE binding factor preparations were concentrated 10 -fold and $5 \mathrm{ml}$ of the concentrated material were absorbed with $1 \mathrm{ml}$ Con A-Sepharose or PNA-agarose overnight at $4^{\circ} \mathrm{C}$. After recovering the effluent supernatants, the beads were washed extensively with PBS. Con A-Sepharose was eluted with $5 \mathrm{ml} 0.2 \mathrm{M} \alpha$-methyl-Dmannoside whereas PNA-agarose was eluted with $5 \mathrm{ml} 0.1 \mathrm{M}$ D-galactose (11). The effluent and eluate fractions were dialyzed against RPMI-1640 medium and adjusted to their original volumes before testing for IgEpotentiating activity.

Radioimmunoassay (RIA) for IgE. Duplicate samples from each culture were analyzed for their IgE content. The RIA for IgE was performed in flexible flat-bottom microtiter plates (Cooke Laboratory Products, Alexandria, VA). The wells were filled with $0.1 \mathrm{ml}$ of a $10 \mu \mathrm{g} / \mathrm{ml}$ solution of a 1:1 mixture of two monoclonal antihuman IgE FC-specific antibodies. These two antibodies (nos. 8 and 9) were a kind gift of Dr. Siraganian, National Institutes of Health, Bethesda, MD). After incubation for 16 $h$, the coating solution was removed, and the wells were washed and blocked with $10 \%$ horse serum (HS) in PBS for $2 \mathrm{~h}$. After washing 3 times with PBS containing $1 \% \mathrm{HS}, 0.1 \mathrm{ml}$ of culture supernatant or of IgE standard was added to each of the triplicate wells and incubated for $16 \mathrm{~h}$ in a humidified chamber at room temperature. The wells were then washed 2 times with PBS-1\% HS containing $0.5 \%$ Tween 20 and twice with PBS- $1 \% \mathrm{HS}$, and then $0.1 \mathrm{ml}$ of Phadebas radioallergosorbent test ${ }^{125}$ I-anti-human IgE (ND) (Pharmacia Fine Chemical; sp. act., $12 \mu \mathrm{Ci}$ / $\mu \mathrm{g})$ was added to each well. $6 \mathrm{~h}$ later, the radiolabeled anti-IgE was re- moved. Wells were then washed 3 times with PBS-1\% HS and 8 times under running distilled water. The wells were cut out and counted in a gamma spectrometer (Tracor Analytic, Elk Grove Village, IL). Standard curves were constructed using dilutions of the IgE standards obtained from Pharmacia Fine Chemical. The cpm bound per well in the background wells were $321 \pm 28$, whereas the cpm bound at $12,000 \mathrm{pg} \mathrm{IgE/}$ $\mathrm{ml}$ was $14,856 \pm 148$. The concentration of IgE in the supernatants was read from the standard curve. The lower limit of sensitivity of this assay varied from $150-300 \mathrm{pg} / \mathrm{ml}$.

The specificity and sensitivity of our IgE RIA was confirmed in a recently completed multi-institutional study coordinated by the Mayo Clinic (Drs. Yunginger, Helm, and Gleich; manuscript in preparation). Coded samples with varying quantities of polyclonal $\mathrm{IgE}$ in the presence of other immunoglobulin isotypes sent to our laboratory were evaluated using our IgE RIA. We did not measure falsely elevated IgE values in any test sample, and thus, ruled out the possibility of cross-reactivity with other isotypes. Furthermore, values of $\mathrm{IgE}>300 \mathrm{pg} \mathrm{IgE} / \mathrm{ml}$ were measured accurately within $20 \%$ of expected values.

$I g G$ determination by RIA. IgG in culture supernatants was measured by a solid-phase competitive RIA as previously described (10).

Isolation of $B$ lymphocytes. Peripheral blood mononuclear cells were isolated from heparinized peripheral blood by ficoll-hypaque density gradient centrifugation. The isolated peripheral blood mononuclear cells were washed 3 times in Hanks' balanced salt solution and suspended in RPMI 1640 medium containing 10\% fetal calf serum. Suspensions of PBMC were depleted of adherent cells by allowing them to incubate for $1 \mathrm{~h}$ at $37^{\circ} \mathrm{C}$ in plastic petri dishes $\left(5 \times 10^{6} \mathrm{cells} / \mathrm{ml}\right)$. Cell suspensions enriched in $\mathrm{B}$ cells were prepared by rosetting nonadherent mononuclear cells with sheep red cells (E) pretreated with neuraminidase and recovering the non-rosette-forming cells by centrifugation over ficoll-hypaque, as previously described (14). After repeating the rosetting procedure a second time, the non-rosette-forming cells contained $70-85 \%$ surface Ig-positive cells and $<2 \% \mathrm{E}+$ cells.

Assay for IgE-potentiating activity. Plasma-derived IgE-binding factors previously dialyzed against RPMI were assessed for their capacity to enhance IgE synthesis by cultures of B cells obtained from 7 subjects with allergic rhinitis whose serum IgE levels ranged from 200-400 IU/ $\mathrm{ml}$, respectively, and on B cells from 7 normal subjects (serum IgE of $<20 \mathrm{IU} / \mathrm{ml})$.

The E-rosette-negative cells were washed and resuspended in RPMI 1640 with $10 \%$ fetal calf serum at a concentration of $1.0 \times 10^{6} \mathrm{cells} / \mathrm{ml}$. The cells were placed in $0.5-1-\mathrm{ml}$ volumes $(12 \times 75-\mathrm{mm}$ plastic tubes $)$ in the presence or absence of IgE-binding factor preparations at a final concentration of $10 \%$. After $7 \mathrm{~d}$ the supernatants were collected, and their IgE and IgG contents were determined. All cultures were done in triplicate. Preformed IgE was determined by acid treatment of B cells on day 1 of culture as recently described by Turner et al. (15). After 7 $\mathrm{d}$ of culture, supernatants were collected and their IgE and IgG contents determined. De novo or net IgE synthesis was calculated by subtracting the values for IgE obtained in day 1 acid-treated cell pellets, i.e., preformed $\mathrm{IgE}$, from IgE values of day 7 supernatants.

Detection of IgE-binding factor. IgE-binding factors were detected by their ability to inhibit rosette formation of the $\mathrm{Fc}$ receptor $\left(\mathrm{Fc}_{\mathrm{e}} \mathrm{R}\right)$ bearing RPMI 8866 cells (the kind gift of Dr. K. Ishizaka) with fixed ox erythrocytes coated with human IgE (E'-IgE) as described by Ishizaka and Sandberg (5). To increase the sensitivity of the assay for rosette inhibition, E'-IgE were prepared by sensitizing fixed ox erythrocytes with $0.02 \mathrm{mg}$ of human IgE (P.S.)/ml (16). With these indicator cells, depending on culture conditions, $25-50 \%$ of RPMI 8866 cells formed rosettes. Plasma filtrates were concentrated 10-fold, filtered through Diaflo CF50A membranes to remove detectable levels of IgE, and dialyzed against RPMI. $E^{\prime}$-IgE were preincubated with the plasma filtrate to be tested and RPMI 8866 cells were added to the suspension for rosette formation. IgE-binding factor activity was expressed as percentage of rosette inhibition. A minimum of 500 cells were counted for each sample, and all determinations were done in a blinded fashion. For the determination of $\mathrm{Fc}_{\boldsymbol{f}} \mathrm{R}(+)$ cells, the percentage of rosette-forming cells with ox red cells coated with human serum albumin was subtracted from the percentage of rosette-forming 
cells with $E^{\prime}-\operatorname{IgE}$. The experimental error for determination of the proportion of $\mathrm{Fc}_{e} \mathbf{R}(+)$ cells was less than $15 \%$.

Expression of data. Results reported in this paper are expressed as mean \pm 1 SD. Statistical analysis was performed with the two-tailed Student's $t$ test.

\section{Results}

Presence of IgE-binding factors in plasma filtrates. Table I shows that plasma filtrates from the four patients with HIE inhibited rosette formation of $\mathrm{Fc}_{\epsilon} \mathrm{R}(+)$ RPMI 8866 cells with $\mathrm{E}^{\prime}-\mathrm{IgE}$ by $56,71,48$, and $35 \%$, respectively. The affinity of this rosetteinhibiting activity for IgE was then examined by absorbing plasma filtrates from each donor with human IgE-Sepharose and recovering the IgE-binding factor(s) by elution with glycine buffer, pH 3. Rosette-inhibiting activity was lost following absorption with human IgE-Sepharose beads and was recovered in the eluates from these beads (Table I). Absorption of HIE plasma filtrates over human IgG-Sepharose did not result in loss of activity and eluates from these beads were devoid of rosette inhibition capacity.

These results suggest that the rosette-inhibiting activity of HIE plasma was due to the presence of IgE-binding factors.

Enhancement of IgE synthesis by HIE plasma IgE-binding factors. The functional activity of IgE-binding factors purified from HIE plasma and normal nonatopic plasma was assessed. Plasma IgE-binding factors eluted from IgE-Sepharose were dialyzed against RPMI, reconstituted to original plasma filtrate volume, and added at a 1:10 dilution to cultures containing $B$ cells obtained from normal subjects or patients with allergic rhinitis. All preparations of IgE-binding factors from HIE and normal plasma used in these experiments caused significant inhibition of rosette formation between IgE-coated ox erythrocytes and the $F_{c} R(+) R P M I-8866$ cell line (see Tables I and II).

In Table II, plasma IgE-binding factors derived from the four different HIE patients were tested for their effect on IgE and IgG synthesis by B cells from patients with perennial allergic rhinitis. In these experiments, IgE-binding factors from three of the four HIE plasmas (patients 1, 2, and 3) significantly enhanced IgE synthesis $(P<0.01)$ by $B$ cells from four different patients with perennial allergic rhinitis without affecting their IgG synthesis $(P>0.4)$. In contrast, IgE-binding factors derived from normal nonatopic donors failed to cause any enhancement of IgE or IgG synthesis in the same experiment. There was no significant difference in IgE or IgG synthesis by B cell cultures receiving IgE-binding factor(s) from patient 4 vs. medium alone $(P>0.1)$.

The effect of IgE-binding factors from patient 2 was studied on a panel of B cells obtained from seven normal subjects (serum $\mathrm{IgE}<20 \mathrm{IU} / \mathrm{ml}$ ) and from three patients with seasonal ragweed or grass-induced allergic rhinitis (SAR) during and 6 mo after pollen exposure. Fig. 1 summarizes the data obtained in these experiments. B cells from the seven normal donors failed to synthesize any detectable IgE regardless of the presence or absence of added IgE-binding factor. B cells obtained from three patients with SAR during pollen exposure exhibited spontaneous IgE synthesis. In each of the three B cell cultures, net IgE synthesis was significantly enhanced $(P<0.01)$ in the presence of IgEbinding factor compared with medium. When B cells were obtained from the same three allergic donors at 6 mo following pollen exposure at a time when the patients were asymptomatic, the B cells did not spontaneously synthesize IgE in culture nor were they induced to synthesize IgE in the presence of IgE-binding factors from HIE plasma.

IgG synthesis was not enhanced by HIE plasma IgE-binding factor in any of the experiments (data not shown).

Physiochemical properties of human IgE-potentiating factors. The affinity of HIE plasma-derived IgE-potentiating factor(s) for Con A or PNA was assessed. Purified plasma IgE-binding factors from HIE patients 2, 3, and 4 (Table II) were incubated either with Con A-Sepharose or PNA-agarose after collecting the supernatants (effluent). The material bound to the beads was then eluted with $\alpha$-methyl-mannoside or D-galactose, respectively; dialyzed against RPMI culture medium; concentrated to

Table I. Binding of HIE Plasma-derived Rosette-inhibiting Factor to IgE-Sepharose*

\begin{tabular}{|c|c|c|c|c|}
\hline \multirow{2}{*}{$\begin{array}{l}\text { Plasma filtrate } \\
\text { fractionation }\end{array}$} & \multicolumn{4}{|c|}{ No. of rosettes per 500 RPMI- 8866 cells in the presence of plasma filtrate } \\
\hline & 1 & 2 & 3 & 4 \\
\hline Medium control & $186 \pm 21(0)+\S$ & $165 \pm 19(0)$ & $171 \pm 15(0)$ & $169 \pm 11(0)$ \\
\hline Unfractionated & $81 \pm 9(56)^{\prime \prime}$ & $64 \pm 10(71)^{11}$ & $89 \pm 7(48)^{\prime \prime}$ & $109 \pm 6(35)^{\prime \prime}$ \\
\hline \multicolumn{5}{|l|}{ IgE-sepharose; } \\
\hline Effluent & $182 \pm 24(2)$ & $158 \pm 21(4)$ & $167 \pm 19(2)$ & $169 \pm 16(0)$ \\
\hline Eluate & $72 \pm 15(61)^{11}$ & $57 \pm 11(65)^{11}$ & $94 \pm 8(45)^{11}$ & $118 \pm 14(30)^{\prime \prime}$ \\
\hline \multicolumn{5}{|l|}{ IgG-sepharose } \\
\hline Effluent & $84 \pm 6(55)^{\prime \prime}$ & $51 \pm 7(69)^{\prime \prime}$ & $97 \pm 10(43)^{\prime \prime}$ & $106 \pm 12(37)^{\prime \prime}$ \\
\hline Eluate & $187 \pm 26(0)$ & $157 \pm 18(5)$ & $166 \pm 20(3)$ & $170 \pm 21(0)$ \\
\hline
\end{tabular}

\footnotetext{
* Plasma filtrates from patients with HIE were absorbed with human IgE (P.S.) = sepharose or human IgG-sepharose, and the beads eluted at acid pH. IgE-binding factors in unfractionated filtrates and in the effluent and eluate fractions of the immunoglobulin-coupled beads were assessed by rosette inhibition of RPMI 8866 cells with ox erythrocytes coated with human IgE. Rosette inhibitory activity was measured in separate assays for each plasma filtrate. ¥ Values represent the mean \pm SEM of rosettes formed between IgE-coated ox erythrocytes with a total of 500 RPMI-8866 cells in the presence or absence of HIE plasma IgE-binding factors. § The mean percent rosette inhibition of each plasma filtrate fraction is given within parenthesis. "Statistically significant $(P<0.01)$ inhibition of rosette formation by the plasma filtrate fraction as compared with medium control.
} 
Table II. Effect of IgE-binding Factors from HIE Plasma on IgE Synthesis In Vitro

\begin{tabular}{|c|c|c|c|}
\hline $\begin{array}{l}\text { B cell } \\
\text { donor }\end{array}$ & $\begin{array}{l}\text { Source of IgE- } \\
\text { binding factor }\end{array}$ & $\begin{array}{l}\text { Net IgE } \\
\text { synthesis }\end{array}$ & $\begin{array}{l}\text { Net IgG } \\
\text { synthesis }\end{array}$ \\
\hline & & $p g / m l$ & $n g / m l$ \\
\hline \multirow[t]{5}{*}{1} & Medium only & $407 \pm 115$ & $119 \pm 17$ \\
\hline & Patient no. 1 & $1,334 \pm 150$ & $121 \pm 16$ \\
\hline & 2 & $3,950 \pm 501$ & $123 \pm 25$ \\
\hline & 3 & $1,301 \pm 189$ & $120 \pm 17$ \\
\hline & 4 & $432 \pm 38$ & $117 \pm 22$ \\
\hline \multirow[t]{5}{*}{2} & Medium only & $350 \pm 76$ & $38 \pm 7$ \\
\hline & Patient no. 1 & $1,126 \pm 38$ & $25 \pm 5$ \\
\hline & 2 & $3,634 \pm 360$ & $39 \pm 10$ \\
\hline & 3 & $1,017 \pm 255$ & $36 \pm 4$ \\
\hline & 4 & $374 \pm 36$ & $40 \pm 6$ \\
\hline \multirow[t]{7}{*}{3} & Medium only & $460 \pm 35$ & $142 \pm 15$ \\
\hline & Patient no. 1 & $2,210 \pm 55$ & $138 \pm 20$ \\
\hline & 2 & $4,190 \pm 219$ & $143 \pm 15$ \\
\hline & 3 & $2,710 \pm 38$ & $140 \pm 22$ \\
\hline & Control no. 1 & $300 \pm 10$ & $145 \pm 10$ \\
\hline & 2 & $180 \pm 35$ & $142 \pm 22$ \\
\hline & 3 & $450 \pm 17$ & $140 \pm 20$ \\
\hline \multirow[t]{7}{*}{4} & Medium only & $300 \pm 50$ & $105 \pm 15$ \\
\hline & Patient no. 1 & $975 \pm 40$ & $97 \pm 10$ \\
\hline & 2 & $1,950 \pm 70$ & $111 \pm 20$ \\
\hline & 3 & $1,425 \pm 35$ & $107 \pm 12$ \\
\hline & Control no. 1 & $210 \pm 20$ & $102 \pm 10$ \\
\hline & 2 & $245 \pm 7$ & $109 \pm 15$ \\
\hline & 3 & $230 \pm 10$ & $115 \pm 22$ \\
\hline
\end{tabular}

Affinity-purified IgE-binding factors derived from plasma of four different HIE patients and three nonatopic controls were tested for their ability to enhance ongoing IgE synthesis by B cells from four patients with perennial allergic rhinitis. The IgE-binding activity of control sera 1,2 , and 3 as determined by percent rosette inhibition was 45,51 , and 28 , respectively. Net de novo IgE or IgG synthesis was calculated by subtracting Ig obtained by acid treatment of cell pellets on day 1 of cultures from Ig present in culture supernatants after $7 \mathrm{~d}$ of culture. Preformed IgE was $275 \pm 25 \mathrm{pg} / \mathrm{ml}$ in B cell donor no. 1 and $375 \pm 25$ $\mathrm{pg} / \mathrm{ml}$ in $\mathrm{B}$ cell donor no. $2,215 \pm 17 \mathrm{pg} / \mathrm{ml}$ in $\mathrm{B}$ cell donor no. 3 , and $160 \pm 10 \mathrm{pg} / \mathrm{ml}$ in $B$ cell donor no. 4 .

original plasma filtrate volume; and tested for its effect at a final dilution of 1:10 on IgE production by $B$ cells from the two patients with allergic rhinitis.

The results shown in Fig. $2 A$ and $B$ indicate that all of the IgE-potentiating activity as well as most rosette inhibitory activity found in HIE plasma 2 and HIE plasma 3 bound to Con ASepharose and was recovered by elution with $\alpha$-methyl-D-mannoside. The Con A eluate from HIE plasma 2 caused a fourfold enhancement of IgE synthesis $(P<0.001)$ and the Con A eluate from HIE plasma 3 caused a fivefold enhancement of IgE synthesis $(P<0.01)$. In contrast, the IgE-potentiating activity failed to bind to PNA-agarose. Fig. $2 C$ shows results of the lectin column fractionation from HIE patient 4 whose unfractionated IgE-binding factors had no significant IgE-enhancing activity. Following fractionation over Con A-Sepharose, the Con A effluent caused $80 \%$ (Table II) suppression of spontaneous IgE production by $\mathrm{B}$ cells from the allergic rhinitis patient $(P<0.01)$.

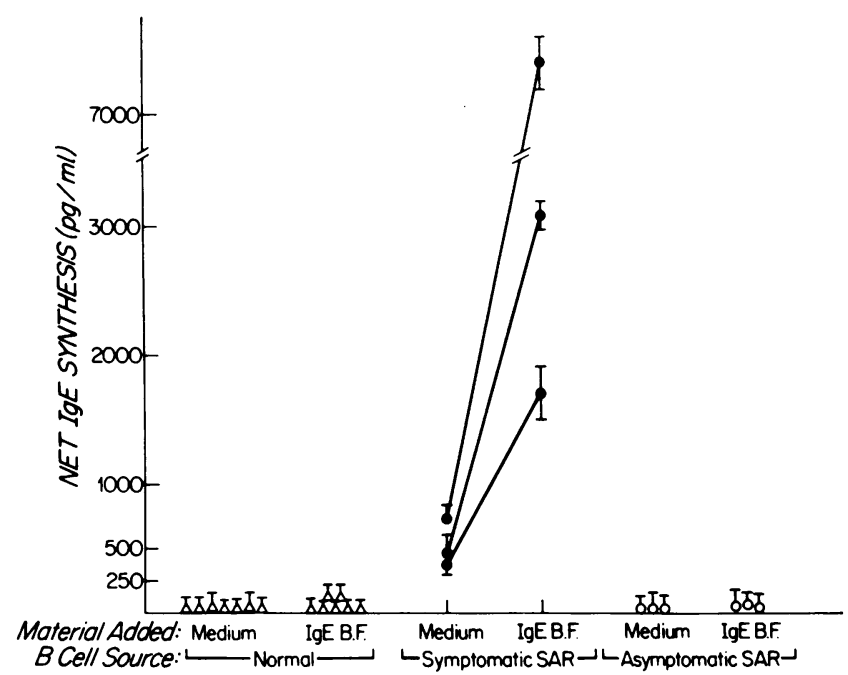

Figure 1. Effect of human IgE-potentiating factor(s) on IgE synthesis by $B$ cells from different donors. B cells from seven normal nonatopic donors $(\Delta)$, and 3 patients with SAR studied during pollen exposure $(\bullet)$ and 6 mo after pollen exposure (O) were stimulated with plasma IgE-binding factors (IgE B.F.) from patient 2. Net IgE synthesis in 7-d cultures was determined by subtracting IgE present in acid-treated, day 1 cell pellets from IgE present in supernatants of the 7-d cultures. Preformed IgE was: $<200 \mathrm{pg} / \mathrm{ml}$ for normal nonatopic donors;

$175 \pm 25,280 \pm 35$, and $390 \pm 45$ for patients with symptomatic SAR; and $200 \pm 25,250 \pm 27$, and $360 \pm 35$ for patients with asymptomatic SAR.

In contrast, the Con A-Sepharose eluate caused a twofold enhancement of net IgE production $(P<0.01)$ by the same $B$ cells. The rosette inhibition assay revealed similar levels of IgE-binding factor in both the Con A effluent and Con A eluate fractions of patient 4. Conversely, IgE-enhancing activity from HIE patient no. 4's plasma was observed in the effluent from PNA-Sepharose whereas IgE-suppressor activity was found in the eluate of PNASepharose. These results indicate that IgE binding factors from patient no. 4 contained a mixture of IgE-suppressive and IgEenhancing activity, the combination of which had no significant effect on IgE synthesis.

The molecular mass of the IgE-potentiating factors was estimated by gel filtration through a Sephadex G-75 column. Plasma IgE-binding factors purified from HIE patient 2 (Table II) was concentrated 100-fold by ultrafiltration (Amicon YM2; Amicon Corp.) in the presence of a proteolytic enzyme inhibitor cocktail (see Methods), applied to a Sephadex G-75 column in the presence of bovine serum albumin, and the eluted fractions dialyzed against RPMI culture medium prior to testing for their ability to enhance IgE synthesis by B cells from two atopic subjects. The same results were obtained with $B$ cells from each atopic donor. As shown in Fig. 3, IgE-potentiating activity from both HIE plasma was associated with two separate peaks. The lower molecular mass peak eluted immediately before that of ribonuclease $A(12,800)$, whereas the higher molecular mass peak eluted between ovalbumin $(48,000)$ and bovine serum albumin $(67,000)$. The two peaks of IgE-potentiating activity were estimated to have a molecular size of 15,000 D and 60,000 D.

\section{Discussion}

The present report documents the existence of IgE-binding factors in plasma derived from patients with HIE. Plasma filtrates 


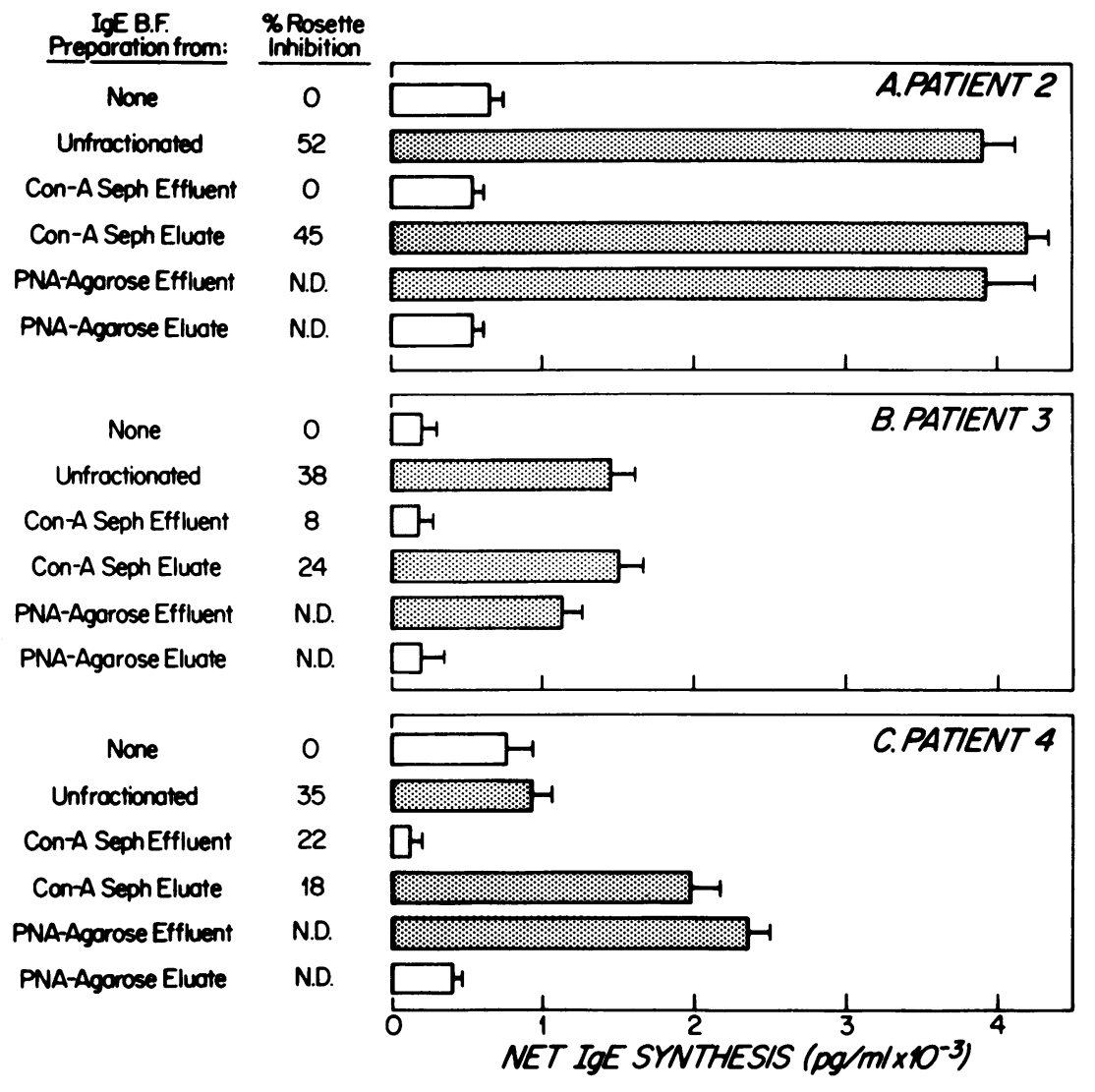

Figure 2. Human IgE-potentiating factor binds to Con A-Sepharose but not PNA-Sepharose. Affinity-purified plasma IgE-binding factors from patient $2(A)$. Patient $3(B)$ and patient $4(C)$ were each absorbed with Con A-Sepharose and PNA-Sepharose, and the beads were eluted with $\alpha$-methyl mannoside and D-galactose. IgE-binding factors from patients 2 and 4 was assayed on B cells from the same donor with perennial allergic rhinitis on two separate occasions. IgE-binding factors from patient 3 was assayed on a second donor with perennial allergic rhinitis. Preformed IgE was $250 \pm 30$ in experiment $1,380 \pm 30$ in experiment $2,285 \pm 20$ in experiment 3.

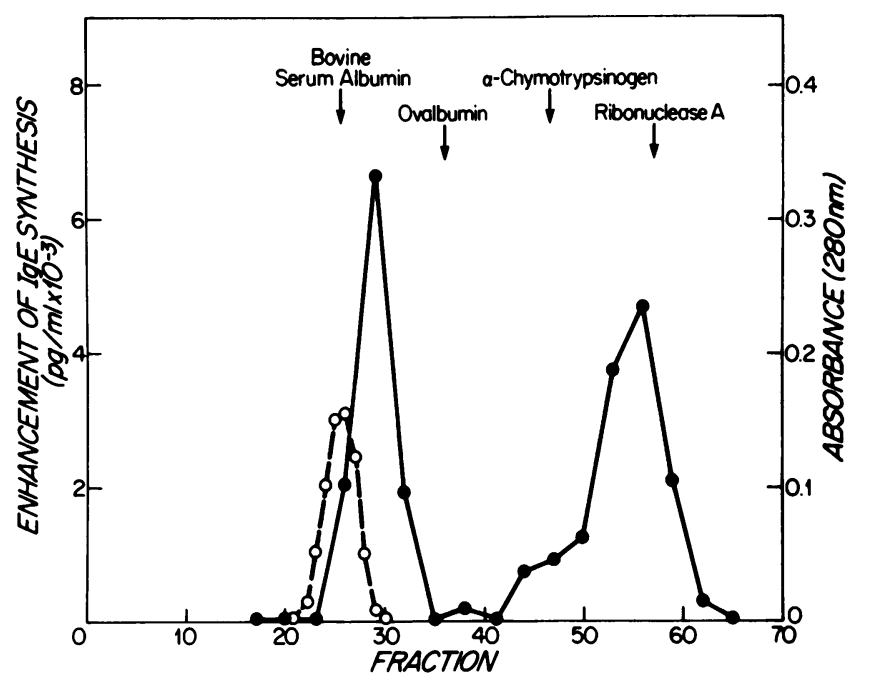

Figure 3. Gel filtration of affinity-purified plasma IgE-binding factors from HIE patient 2 (panel $A$ ) (Tables I and II). IgE-binding factors were concentrated to 1:100 of original plasma volume and $1 \mathrm{ml}$ of the concentrated IgE-binding factor preparation was applied to a Sephadex G-75 column together with bovine serum albumin (- - - - ). Every third fraction was dialyzed against RPMI and assessed for its ability to enhance IgE synthesis by B cells from two separate donors with perennial allergic rhinitis. Similar results were obtained using both B cell donors. The results from one such experiment are shown. Enhancement of IgE synthesis (-•-) was calculated by subtracting spontaneous net IgE synthesis of untreated atopic lymphocytes ( 975 $\mathrm{pg} \mathrm{IgE} / \mathrm{ml}$ ) from net IgE synthesis of atopic lymphocyte cultures stimulated with Sephadex G-75 fractions. Preformed IgE was 450 pg IgE/ $\mathrm{ml}$. Two peaks containing IgE-enhancing activity were found: one at $15,000 \mathrm{D}$, the other at $60,000 \mathrm{D}$. from four of four patients with HIE inhibited rosette formation between $\mathrm{Fc}_{\mathrm{\epsilon}} \mathrm{R}+\mathrm{RPMI} 8866$ cells and ox erythrocytes coated with human IgE. The rosette inhibitory activity bound to human IgE-Sepharose but not to human IgG-Sepharose (Table I). IgEbinding factors from three of four HIE plasmas tested enhanced ongoing IgE but not IgG synthesis by B cells from atopic patients (Fig. 1). In contrast, IgE-binding factors from three of three normal nonatopic plasmas failed to enhance IgE synthesis when tested simultaneously on the same atopic B cell donors. Patient no. 4 had a mixture of IgE-suppressive and IgE-potentiating activity in her plasma. This patient did not have the lowest serum IgE amongst the four patients studied. This is not surprising as IgE production occurs primarily in lymphoid tissues adjacent to the respiratory and gastrointestinal tracts $(17,18)$ where the proportion of IgE-enhancing to IgE-suppressive factor may differ from plasma. Indeed, Hirashima et al. (19) reported that serum of rats treated with complete Freund's adjuvant contained both IgE-potentiating factor and IgE-suppressive factor, while their spleen cells formed only IgE-suppressive factor.

IgE-potentiating activity from HIE plasma enhanced ongoing IgE synthesis by $B$ cells from patients with perennial allergic rhinitis and $B$ cells from patients with SAR during pollen exposure, but not $B$ cells which made no spontaneous IgE in vitro, i.e., B cells from nonatopic donors or patients with SAR with no recent pollen exposure. These results are consistent with our previous observations (10) that IgE-binding factors released by $\mathrm{Fc}_{\boldsymbol{e}} \mathrm{R}(+) \mathrm{T}$ cell lines derived from HIE patients enhance IgE synthesis by in vivo activated IgE-bearing $B$ cells from atopic patients. In an earlier study by Saryan et al. (8), we had demonstrated that culture supernatants of unfractionated $T$ cells from HIE patients contained soluble factors which induced normal B cells to synthesize IgE. These crude HIE T cell supernatants 
were likely to have contained additional B cell-activating factors required to bring resting $B$ cells to a level of activation that was responsive to IgE-binding factors.

In the present study, the human IgE-enhancing activity from HIE plasma shared several physiochemical characteristics with the rat $\mathrm{T}$ cell-derived IgE-potentiating factor described by Yodoi et al. (4). Human IgE-enhancing activity had marked affinity for Con A but only minimal affinity for PNA. These results suggest that human IgE-potentiating factor contains $N$-linked, mannose-rich oligosaccharide. Gel filtration of IgE-binding factors from HIE plasma through a Sephadex G-75 column followed by biologic assay of each fraction revealed two peaks of IgEenhancing activity: one with a molecular size of $15,000 \mathrm{D}$, the other with a molecular size of $60,000 \mathrm{D}$. The detection of a $60,000 \mathrm{D}$ IgE-binding factor despite filtration of plasma through CF50A membranes three times was not surprising because although IgE could not be detected in the plasma filtrates, substantial amounts of serum albumin passed through the CF50A membranes (Leung and Geha, unpublished observations). Rat IgE-binding factors of $15,000,30,000$, and $60,000 \mathrm{D}$ have been described by Ishizaka and co-workers $(3,20)$. The latter investigators have suggested that the higher molecular size IgE-binding factor may be cleaved to yield the 15,000 molecular size IgEbinding factor. Preliminary investigations in our laboratory indicate that $\mathrm{Fc}_{\boldsymbol{e}} \mathrm{R}(+) \mathrm{T}$ cell lines from patients with HIE secrete IgE-potentiating factors with a molecular size of 15,000 and $60,000 \mathrm{D}$ (21). Studies are currently in progress to determine the relationship between these two molecules.

In conclusion, we have demonstrated circulating IgE-binding factors which potentiate IgE synthesis in the plasma of patients with HIE. In contrast, IgE-binding factors from nonatopic sera contain predominantly IgE-suppressive activity (11). These results suggest that IgE-binding factors play an important role in the in vivo regulation of human IgE synthesis.

\section{Acknowledgments}

This work was supported by the U. S. Public Health Service grants AM31925-01, AI-05877, and AI-20373-01, and by a grant from the National Foundation, March of Dimes. Dr. Leung is the recipient of a New Investigator Research Award 5R23 HL30082-02 and Dr. Geha is the recipient of an Allergic Diseases Academic Award K07 AI-0440-02.

\section{References}

1. Ishizaka, K. 1983. Regulation of IgE response by IgE-binding factors. Monogr. Allergy. 18:52-60.

2. Suemura, M., J. Yodoi, M. Hirashima, and K. Ishizaka. 1980. Regulatory role of IgE binding factors from rat $\mathrm{T}$ lymphocytes. I. Mechanisms of enhancement of IgE response by IgE-potentiating factor. $J$. Immunol. 125:148-154.

3. Hirashima, M., J. Yodoi, and K. Ishizaka. 1980. Regulatory role of IgE-binding factors from rat T lymphocytes. III. IgE-specific suppressive factor with IgE-binding activity. J. Immunol. 125:1442-1448.
4. Yodoi, J., M. Hirashima, and K. Ishizaka. 1982. Regulatory role of IgE-binding factors from rat $\mathrm{T}$ lymphocytes. V. The carbohydrate moieties in IgE-potentiating factors and IgE-suppressive factors. J. Immunol. 128:289-295.

5. Ishizaka, K., and K. Sandberg. 1981. Formation of IgE binding factors by human T lymphocytes. J. Immunol. 126:1692-1696.

6. Buckley, R. H., B. B. Wray, and E. Z. Belmaker. 1972. Extreme hyperimmunoglobulinemia $\mathrm{E}$ and undue susceptibility to infection. Pediatrics. 49:59-69.

7. Geha, R. S., E. L. Reinherz, D. Leung, K. T. McKee, S. F. Schlossman, and F. S. Rosen. 1981. Deficiency of suppressor T cells in the hyperimmunoglobulinemia E syndrome. J. Clin. Invest. 68:783-791.

8. Saryan, J. A., D. Y. M. Leung, and R. S. Geha. 1983. Induction of human IgE synthesis by a factor derived from $\mathrm{T}$ cells of patients with hyper IgE states. J. Immunol. 130:242-247.

9. Romagnani, S., E. Maggi, G. F. DelPrete, and M. Ricci. 1983. IgE synthesis in vitro induced by $\mathrm{T}$ cell factors from patients with elevated serum IgE levels. Exp. Immunol. 52:85-88.

10. Young, M. C., D. Y. M. Leung, and R. S. Geha. 1984. Production of IgE potentiating factor in man by $\mathrm{T}$ cell lines bearing $\mathrm{Fc}$ receptors for IgE. Eur. J. Immunol. 14:871-878.

11. Leung, D. Y. M., C. Brozek, R. Frankel, and R. S. Geha. 1984. IgE specific suppressor factors in normal human serum. Clin. Immunol. Immunopathol. 32:339-350.

12. Dejuchi, H., A. Suemura, A. Ishizaka, Y. Ozaki, S. Kishimoto, Y. Yamamura, and T. Kishimoto. 1983. IgE class-specific suppressor T cells and factors in humans. J. Immunol. 131:2751-2756.

13. Leung, D. Y. M., N. L. Wood, and R. S. Geha. 1985. Reversal of cellular abnormalities in the hyper IgE (HIE) syndrome following plasmapheresis. Clin. Res. 33:161A. (Abstr.)

14. Geha, R. S., F. S. Rosen, and E. Merler. 1973. Identification and characterization of subpopulations and lymphocytes in human peripheral blood after fractionation on discontinuous gradients of albumin. J. Clin. Invest. 52:1726-1734.

15. Turner, K. J., P. G. Holt, B. J. Holt, and K. J. Cameron. 1983. In vitro synthesis of IgE by human peripheral blood leucocytes. III. Release of preformed antibody. Clin. Exp. Immunol. 51:387-394.

16. Huff, T. F., and K. Ishizaka. 1984. Formation of IgE binding factors by human T-cell hybridomas. Proc. Natl. Acad. Sci. USA. 81: 1514-1518.

17. Brown, W. R., B. K. Borthistle, and S. T. Chen. 1975. Immunoglobulin $\mathrm{E}$ and IgE-containing cells in human gastrointestinal fluids and tissues. Clin. Exp. Immunol. 20:227-237.

18. Callerane, M. L., J. J. Londemi, and K. Ishizaka. 1971. Immunoglobulins in bronchial tissues from patients with asthma, with special respond to immunoglobulin E. J. Allergy. 47:187-195.

19. Hirashima, M., J. Yodoi, and K. Ishizaka. 1980. Regulatory role of IgE-binding factors from rat $\mathrm{T}$ lymphocytes. IV. Formation of IgEbinding factors in rats treated with complement Freund's adjuvant. $J$. Immunol. 125:2154-2160.

20. Martens, C. L., T. F. Huff, P. Jardieu, M. L. Trounstine, R. L. Coffman, K. Ishizaka, and K. W. Moore. 1985. cDNA clones encoding IgE-binding factors from a rat-mouse T cell hybridoma. Proc. Natl. Acad. Sci. USA. 82:2460-2464.

21. Young, M. C., D. Y. M. Leung, and R. S. Geha. 1985. Production of IgE potentiating factor by $\mathrm{Fc}_{\mathfrak{\epsilon}} \mathrm{R}+$ human $\mathrm{T}$ cell lines. J. Allergy Clin. Immunol. 75(Pt. 2):109. (Abstr.) 